\title{
Techniques and problems of the isolation of pure cultures of Basidiomycetes
}

\author{
VÁCLAV ŠAŠEK
}

\begin{abstract}
$\bar{S} A \bar{S} E K, V .1978:$ Techniques and problems on the isolation of pure cultures of Basidioincetes. - Karstenia 18 (suppl.).

The basis for any mycological work is primarlly to have the pure culture of the fungus. The majority of the basidiomycetous cultures have been obtained through isolation from the fruit-body tissue but for some special cases the basidiospores, rhizomorphs, mycorrhizas, infected wood or other substrates have been imployed. However, pure cultures of all Basiinfected wood or other substrates have been imployed. However, pure cultures of all Basi
diomycetes species have not been obtained so far. Many species, viz. from the genera Boletus, Russula, Lactarius, Clitocybe, Cortinarius and other simply do not grow under artificial conditions. Mycorrhizal fungi, when grow in pure culture, are generally very slow. The best organismus thus seems to be the wood inhabiting fungi, cultures of which are growing rather fast and many of the species even form fruit-bodies spontaneously. Prosperity of the isolation is affected by some external factors, such as the weather before and during the collection of fruit-bodies, the stage of fruit-bodies, the interval between collection and isolation, and the composition of cultivated medium. The isolation is competed by the identification of the obtained culture. Since no key to the cultures of Basidiomycetes exists so far, not only macroscopic and microscopic characterization but also the comparative study with the existing strains in different collections is necessary.

V. Sasek, Institute of Microbiology, Czechoslovak Academy of Sciences, Budējovickā 1083, 14220 Prague, Czechoslovakia.
\end{abstract}

It is hard to believe that the isolation of pure cultures of Basidiomycetes has already a history of a hundred years. Oscar Brefeld was the first who, in 1877, isolated single basidiospores and obtained a pure culture. The fungus was Armilzaria mellea and the goal of Brefeld's work was to confirm that the organisms known as Rhizomorpha subterranea and $R$. subcutioularis were the vegetative structures belonging to the fruit-bodies of $A$. melzea.

Since Brefeld's time the techniques and methods of isolation of pure cultures of Basidiomycetes have developed substantially, and their survey and demonstration is the aim of the present paper.

The process of obtaining a culture of a basidiomycete can be divided into three steps: 1) collection of material, 2) isolation, 3) purification and identification of the culture.

\section{Collection of material}

Since most cultures have been obtained by isolation from fruit-bodies, this part will deal only with collecting of the fruit-bodies. The excat determination of collected sporophores has been often overlooked and later on, when the culture has been successfully isolated and chanced to be interesting for some reason, this neglect cannot be neutralized. It is important to keep the specimens of sporophores for the possibility of their later re-identification. Very useful is the co-operation with taxonomists for the exact identification of freshly collected material. For future isolation, to avoid possible cross-infection of collected fruit-bodies, it is recommended to transport the individual samples separately wrapped in aluminium foil or wrapping paper or in envelops of an adequate size. It is important to describe the natural substrate (in wood-inhabiting species) or the tree-species under which the fungus was growing (in mycorrhizal fungi), and also the colour, smell, surface and other features of the fruit-body that may later change or disappear.

Success of the isolation from the collected material is affected by some external factors, such as the weather before and during collection and the time lag between collecting and planting. Soaked fruit-bodies collected just after or during rain result often in contamination of the cultures by bacteria and yeasts. Culture isolation from the collected fruit-bodies should be done as soon as possible.Espenshade (1962) even recommended the field laboratory equipment which could be used directly in the respective locality. It is reasonable to isolate on the day of material collection; however, we obtained many viable cultures from fruit-bodies stored 1-2 days in the refrigerator at $4^{\circ} \mathrm{C}$. Pantidou (1961) even observed that tissue from fruit-bodies kept in the refrigerator for 3 days and from fruit -bodies sent by mail and being in transit for up to 40 hours grew well in culture.

Very important is the "physiological state" of fruit-bodies. It means that the fungi should be fresh and in active growth. If possible, the collecting of sporophores of different age is recommended - 
the older mature ones for the spore prints, exsiccati and identification while the immature specimens for the tissue transplantates.

\section{Isolation techniques}

\section{Isolation from fruit-body tissue}

The fruit body should be cut, or preferably broken, under as sterile conditions as possible and a piece of tissue taken with a sterile scalpel transferred on the nutrient medium in a test tube. Some authors recommend surface sterilization of the fruit-body before the procedure by means of ethanol, formaldehyde $(1: 100)$ or mercuric chloride $(0.1 \%)$. According to Nizkovskaya (1969) it is even possible to flame the fruit-body moisted with ethanol. We have got the best results when the mechanically cleaned fruit -body was wiped with a piece of wool moistened with $0.1 \%$ mercuric chloride. Experiences differ concerning the size of tissue to be taken. According to Espenshade \& Griffith (1966) pieces 1 × $1 \mathrm{~mm}$ were usually large enough, but for some Boletaceae they had to be 3-5 $\mathrm{mm}$ in diameter. Watling (1971) recommended a piece of tissue about $3 \mathrm{sq} . \mathrm{mm}$, and in our laboratory we observed that especially for mycorrhizal species the size of explanted tissue should be as big as possible. This is, of course, limited by the size of fruit -body and the fact that extraction of the tissue close to the surface layer which comes in contact with the environment would mean a higher risk of infection.

Important is the observation of Pantidou (1961) that growth rarely occurred from a piece of tissue placed flat on tha agar, whereas tissue placed so that half was immersed in the agar and half projected into the air usually yielded good growth. This observation was also confirmed by Semerdzieva (1965).

The number of isolates from each fruit-body depends on its size and state. If possible, five to six isolates from one fruit-body are sufficient (Semerdžieva 1965, Semerdżieva \& Cejp 1966).

The area from which the tissue should be taken for isolation may differ from one species to another. The isolation is possible from the hymenial part, cap tissue or junction of cap and stem. Isolation from sporophores of Boletaaea is easier from the cap or the junction between cap and stem, whilst in Amanita species the stem or the bulb are more convenient parts for explantation. However, the statement of Watling (1971) is in general valid that most parts of the fruit-body of a basidiomycete may be dormant but the area which is most active for the longest period is often the spore-producing tissue. This is frequently the best place to seek the tissue plug which will be utilized as an inoculum.

Generally, similar cultures are obtained using tissue taken from the stipe and pileus and if some morphological differences appear they last for only a few transfers and later on it is not possible to distinguish if the culture originates from the cap or the stem. The tissue from a young fruit-body generally gives the same type of culture as that from an older one (see Pantidou \& Watling 1970). The sitwation is different when the cultures originate from different natural sources. Whitney \& Bohaychuk (1976) observed morphological and physiological differences in their cultures of Polyporus tomentosus. The cultures originated from decayed wood. The basidiospores or sporophore tissue differed in growth rate, pigmentation and chlamydospore formation. Similarly s. Kowalski in Krakow (personal communication) observed differences in morphology and growth among species of mycorrhizal fungi. The isolates from mycorrhizae and from the fruit-body of the same fungal species grew differently, even the same strain isolated from the fruit-body differed from the culture which was re-isolated from synthetic mycorrhizae.

Isolation from the tissue of resupinate sporophores is often impossible because of frequent contamination of the cultures; here the isolation from basidiospores (see below) is more promising.

An isolation of clavarioid Basidiomycetes was described by Petersen (1972). This author simply inserted a fruit-body branch apex (terminal 2-3 mm) into a slit in the agar medium with a sterile scalpel or razor blade, without any surface sterilization of the fungus tissue. Because of the high probability of contamination the author made several replicates of each potential isolate.

A simple and suitable method of isolation from the tissue of tiny fruit-bodies, from which it is practically impossible to pick up aseptically a piece of the inner part of tissue, is used in the Leningrad Laboratory of Biochemistry of Lower Plants. The whole small fruit-body is soaked for a second in ethanol, flamed and immediately cut with sterile scissors above the surface of nutrient medium in an open Petri dish. By this technique it is possible to get several pieces from one small fruit-body; some of them, of course, do not survive the drastic decontamination, but the number of viable tissue bits is relatively high.

\section{Isolation from basidiospores}

This technique has been described by many authors, but generally there are two methods: basidiospores are either allowed to discharge directly on nutrient medium or are collected separately as a spore-print of the hymenial part of the fruit-body. The first approach is faster, the second one allows one to obtain (after proper dilution of spore suspension) monokaryotic cultures.

In the first case a piece of the hymenial part is sealed by means of agar or sterile vaseline on the underside of a Petri dish lid so that the pores or gills are over the agar. After the spore discharge (which can take one or several hours) the lid is replaced by another sterilized one. In order to sow basidiospores over a wider area of agar surface it is recommended to seal the hymenial piece 
on the lid non-centrally and to rotate the cover lid periodically. Instead of Petri dishes, test tubes with agar medium can be used (see e.g. Ballal 1967). In this case the hymenial part is sealed by means of a small piece of cut agar over the slant.

A spore-print can be obtained of the sporophore by laying the hymenial part, surface down, on a glass -slide or sterile paper of contrasting colour. After dilution of the spore-mass with sterile water the suspension is spread over the nutrient agar in a Petri dish. After incubarion the germinating spore can be picked up with a needle under a binocular microscope at about 30-60 diameters magnification. When instead of spores the individual colonies are isclated, microscopic or genetic control is necessary to avoid the possibility of getting a dikaryotic mycelium.

For genetic purposes more sophisticated procedures have been developed, such as the isolation of spore-tetrads directly from the basidia (Papazian 1950, Moore 1966, Epp 1977), or the collection of spores from sporophores grown in the laboratory under aseptic conditions (Semerdžieva \& Musílek 1970).

Isolation from basidiospores is connected with the problem that spores of many basidiomycetous species do not germinate under laboratory conditions. Some spores have been induced to germinate, e.g. by means of incubation in a damp chamber (Watling 1963), or on the base of the observation of Fries (1941) that the proximity of other micro-organisms has a positive effect on basidiospore germination.

\section{Isolation from other sources}

Cultures of wood-inhabiting Basidiomycetes can be isolated directly from infected wood. The surface of the wood specimen should be sterilized and a small piece of wood cut out from the layer under the surface and transferred on a nutrient medium. The procedure has been described in detail by Cartwright \& Findlay (1958).

Several basidiomycetous species were also isolated from soil by means of dilution plates and hyphal isolation techniques. The method of isolation of mycorrhizal fungi from mycorrhizae is not complicated but it is laborious. The mycorrhizal roots should be perfectly cleaned mechanically, washed several times with sterile water in a set of test tubes, cut into portions and plated out (see e.g. Shemachanova 1962 , Zak 1973).

\section{Nutrient media}

It is not possible to list here all the media that have been composed for the cultivation of Basidiomycetes (see e.g. Nizkovskaya 1969, Booth 1971), especially because many authors use different extracts of natural materials such as soil, sawdust, straw, leaves, fruit-bodies, dung, various fruits, etc. Solid agar media are generally used, but fruit -body tissue of some slowly growing species start to grow easier when inoculated in a liquid medium. For the isolation it is necessary to use more than one type of medium. In our laboratory we have good experiences with a combination of three media: wort agar (fresh wort from a brewery diluted with water to $8^{\circ} \mathrm{Ball}$; $\mathrm{pH} 5.5,2 \%$ agar), KHO medium ( $\breve{a}$ šek \& Musilek 1967) and Modess agar (1941).

\section{Purification and identification of cultures}

The procedure of isolation is not successful every time. There are practically four possibilities: 1) inoculum does not grow, 2) only contaminating micro-organisms are obtained, 3) the culture is composed of a mixture of micro-organisms, 4) the growing culture seems to be the isolated fungus, The reason in the first case could be that the isolation was done from the dormant part of sporophore or that inadequate medium was used. But often it is due to the fact that many Basidiomycetes (especially some species of the genera Amanita, Clitocybe, Cortinarius, Lactarius and Russula) simply do not grow under artificial conditions.

Contamination of the transferred tissue usually appears a few days after inoculation. Yeasts and bacteria are the first, and also Fungi Imperfecti (Trichodorma viride, Botrytis cinerea, Cladosporium herbarum, Trichothecium roseum and species of genera Penicilizum, Aspergiltus, Fusarium, Verticilitum) can be recognized within a few days by virtue of their characteristic fructification.

In the case that the inoculum is growing but some contamination is also present, purification should be done by several transfers of growing hyphae on a fresh medium. Against bacterial infection the addition of Rose Bengal, streptomycin (or some similar broad-spectrum antibiotic) into the medium is often successful.

In the last case - when growing filaments are observed on the surface of inoculum and seem to be the isolated fungus-mainly experience can teach the investigator how to recognize it. Since cultures of Basidiomycetes do not have enough of pronounced macroscopic or microscopic features, no key for their identification exists. The keys of Nobles (1948) or Pantidou \& Groves (1966) are useful only for a very limited group of Basidiomycetes. Identification according to fruit-body formation is practically neglectable because only some 100 species fructify under laboratory conditions. Moreover, the clamp -connections which should characterize the Basidiomycetes are not present regularly. For instance Semerdzieva (1965), studying 57 species of Basidiomycetes in the form of mycelial cultures, observed clamps in $69 \%$. Even the presence of clamps is not an absolute proof because different species of Basidiomycetes parasitizing one another have been observed (Griffith \& Barnett 1967).

Determination of a culture depends on the study of a combination of macroscopic and microscopic char- 
acteristics throughout development of the culture, and on comparison with other isolates of the same species and other strains from different laboratories. In individual cases the use of serological methods (e.g. Madhosingh 1964), biochemical studies (e.g. Kaarik 1965, Robbers et al. 1964, Cherotchenko 1974) or genetic and electron-microscopic techniques can contribute a great deal to the solution of this problem.

\section{References}

Ballal, S.K. 1967: Certain cultural and physiological variation among some resupinate polypores. J. Tennessee Acad. Sci. 42 (3): 97-103.

Booth, C. 1971: Fungal culture media. In: Booth, C. (ed.), Methods in microbiology 4. - Acad. Press, London \& New York, pp. 49-111.

Brefeld, 0. 1877: Basidiomyceten. - Botanische Untersuchungen uber Schimmelpilze 3: 136-173. Arthur Felix, Leipzig.

Cartwright, K.St.G. \& Findlay, W.P.K. 1958: Decay of timber and its preservation. - H. Maj. Stat. Off., London, $332 \mathrm{pp}$.

Cherotchenko, Yu. P. 1974: Comparative studies on fungal sterins produced by genera Boletus Fr. and Leccinum S.F. Gray belonging to Boletaceae family. (In Russian). - Mikol. i Fitopatol. $8(1): 67-69$.

Epp, B.D. 1977: A rapid method for the isolation of tetrads in higher Basidiomycetes. - Mycologia 69: 210 .

Espenshade, M.A. 1962: A study on the isolation and the cultivation of Basidiomycetes. In:Koda,C.F. (ed.), Development in industrial microbiology. - Plenum Press, New York, Vol. 3, pp. 347-352.

Espenshade, M.A. \& Griffith, E.W. 1966: Tumor -inhibiting Basidiomycetes. Isolation and cultivation in the laboratory. - Mycologia 58 (4): 511-517.

Fries, N. 1941: Über die Sporenkeimung bei einigen Gasteromyceten und mykorrhizabildenden Hymenomyceten. - Arch. Mikrobiol. 12: 266-284.

Griffith, N.T. \& Barnett, H.L. 1967: Mycoparasitism by Basidiomycetes in culture. - Mycologia 59: 149-154.

Kaarik, A. 1965: The identification of the mycelia of wood-decay fungi by their oxidation reactions with phenolic compounds. - Studia Forest. Suecica, (Stockholm) No. 31: 1-80.

Madhosingh, C. 1964: A serological comparison of isolates of Fomes roseus and Fomes subroseus. - Canad. J. Bot. 42: 1677-1683.

Modess, 0. 1941: Zur Kenntnis der Mykorrhizabildner von Kiefer und Fichte. - Symb. Bot. Upsal. 5 (1): 1-147.

Moore, D. 1966: New method of isolating the tetrads of agarics. - Nature 209: 1157-1158.

Nizkovskaya, O.P. 1969: Physiology of fungi. In: Shivrina A.N., Nizkovskaya, O.P., Mattison,
N.L. \& Efimenko, O.M. (eds.), Biosynthetic activity of higher fungi. (In Russian). Izd. Nauka, Leningrad, pp. 60-100.

Nobles, M.K. 1948: Studies in forest pathology. VI. Identification of cultures of wood-rotting fungi. - Canad. J. Res. 26: 281-431.

Pantidou, M.E. 1961: Cultural studies of Boletaceae. Gyrodon merulioides and four species of Boletinus. - Canad. J. Bot. 39: 1149-1162.

Pantidou, M.E. \& Groves, J.W. 1966: Cultural studies of Boletaceae. Some species of Suillus and Fuscoboletinus. - Canad. J. Bot. 44: 13711392 .

Pantidou, M.E. \& Watling, R. 1970: A contribution to the study of the Boletaceae - Suilloidae. - Notes R.B.G. Edinb. 30 (1): 207-237.

Papazian, H.P. 1950: A method of isolating the four spores from a single basidium in Schizophyllum commune. - Bot. Gaz. (Grawfordsville) 112: $139-140$.

Petersen, R.H. 1972: Cultural characters in Ramaria subg. Lentoramaria, and a new taxon. - Amer. J. Bot. 59 (10): 1041-1047.

Robbers, J.E., Brady, L.R. \& Tyler, V.E.,Jr. 1964 : A chemical and chemotaxonomic evaluation of Inocybe species. - Lloydia 27 (3): 192-202.

Šašk, V. \& Musílek, V. 1967: Cultivation and antibiotic activity of mycorrhizal Basidiomycetes. - Fol. Microbiol. (Prague) 12: 515-523.

Semerdžieva, M. 1965: Cultivation and morphological observation of some fungi of family Agaricaceae in vitro. (In Czech.). - Česká Mykol. (Prague) 19 (4): 230-239.

Semerdžieva, M. \& Cejp, K. 1966: Investigation of mycelial growth in some gill fungi under laboratory conditions. - Folia Microbiol. (Prague) 11: 148-154.

Semerdzieva, M. \& Musílek, V. 1970: Wachstum und Entwicklung des Basidiomyceten Oudemansiella mucida. - Ces. Mykol. (Prague) 24: 44-53.

Shemachanova, N.M. 1962: Mycotrophy of woody plants. (In Russian). - Izd. Akad. Nauk SSSR, Moskva, $374 \mathrm{pp}$.

Watling, R. 1963: Germination of basidiospores and production of fructifications of members of the agaric family Bolbitiaceae using Herbareum material. - Nature (London) 197: 717-718.

-"- 1971: Basidiomycetes. Homobasidiomycetidae. In: Booth, c. (ed.), Methods in microbiology. 4, Acad. Press, London \& New York, pp. 219-236.

Whitney, R.D. \& Bohaychuk, V.P. 1976: Growth of Polyporus tomentosus cultures derived from basidiospores, sporophore tissue, and decayed wood. - Canad. J. Bot. 54 (22): 2597-2602.

Zak, B. 1973: Classification of Ectomycorrhizaea. In: Marks, G.C. \& Kozlowski, T.T. (eds.), Ectomycorrhizae, their ecology and physiology.- Acad. Press, New York \& London, pp. 43-78. 